\title{
Cognitive and Emotional Load Influence Response Time of Service Agents: A Large Scale Analysis of Chat Service Conversations
}

\author{
Anat Rafaeli \\ anatr@ie.technion.ac.il
}

\author{
Daniel Altman \\ Technion - Israel Institute of Technology \\ altmand@campus.technion.ac.il
}

\author{
Galit B. Yom-Tov \\ gality@technion.ac.il
}

\begin{abstract}
We highlight two psychological aspects of the load in service work - cognitive load (amount of information customers present) and emotional load (emotions customers present), and examine their effects on response time of service agents, in service conversations conducted using text-based chats. Using operational data of 145,995 chat service conversations, we show that cognitive load and emotional load increase agent response time both between and within service conversations. Our analyses unpack common assumptions that number of customers is identical to amount of work load, and shed light on customer-agent dynamics both between and within service conversations. In studying text-based service communication, which is rapidly expanding and insufficiently studied, we open up exciting opportunities for further research.
\end{abstract}

\section{Introduction}

Studies of service delivery implicitly assume that different customers are equal. For example, studies of call centers define the number of customers as load (c.f., [1]), and goals and assessments of service agents' performance refer to the number of customers handled, and a target for the average call length (e.g., [2]), with little or no attention to aspects of specific customers or specific conversations. Service interactions involve people, however, and people bring personal issues and behaviors that impose different demands on agents. A managerial approach that measures load only in terms of number of customers cannot capture the full extent of effort that service agents must invest. Research on emotional labor (cf. [3, 4]) clearly implies that service work is more than a production line of customers. In this vein, we suggest that service work involves psychological load, which can be cognitive (i.e., the number of words or amount of information an employee must process), and/or emotional (i.e., the emotions customers express) [5]. We propose, and empirically verify, that cognitive and emo- tional load impact employee performance. Our analyses identify influences on agent behavior that should be recognized in management and planning of service systems [6].

Customer service occurs in a stressful work environment [7]; employees are required to balance between customer requests and organizational goals, and expected to provide "service with a smile" [8], although customers are not always right, and often aggressive [3]. Service work is described as the modern sweatshop [9], in large part because work is highly structured and employees are closely monitored in what they can say (or not say), and how long they can spend with a customer [2]. The emphasis on efficiency requires agents to be "ambidextrous", constantly balancing multiple goals (c.f., [10]).

We assert that management and research are still not fully recognizing the stressful predicaments of service work, because the amount of cognitive and emotional load that different service interactions impose on employees are still not recognized. Each customer can present a different set of problems and can display different emotions to an employee, yet research of service delivery does not account for variations between customers. We empirically show that a granulated look at employee work load, that considers variation between customers, impacts employees' response time. Managerially our findings mean that service systems, that must be efficient in order to be competitive (c.f., [10]), must recognize the requirements of different types of customers. Our view of dynamics within service interactions can also help resolve agent burnout and turnover $[11,12,13]$

Some previous research made similar assertions, but available findings (from which we draw our hypotheses) are based either on lab studies (which lack external validity) or on self-reports (which suffer from many limitations, notably social desirability and same source bias, to mention but a few, c.f. [14]). We believe we are the first to document the predicted effects with realtime performance of real-live customer service conver- 
sations. Moreover, we analyze a new and rapidly growing service platform, of text-based conversations. Textbased service is unique in various ways and requires focused research attention. Text based service is useful to address our research question because it records objective measures of the service interaction. Thus, our study contributes novel insights about dynamics within service interactions, using large-scale and fully objective data about the behavior of customers and employees.

\subsection{Contributions}

The overarching contribution of this paper is a granulated view into service conversations, looking at effects of individual customer conversations on service agents. We make several specific contributions:

1. We identify two aspects of psychological load that each customer can create for an agent, defining cognitive and emotional load.

2. We empirically test and document that these psychological aspects influence agents' on real-responsetime to actual customers, which means they influence agent efficiency.

3. We show the effects of these these psychological aspects at the conversational level, showing both effects between different conversations, and effects within segments of specific conversations.

4. We begin to untangle social influence effects in dyadic service conversations, of behavior of a customer who is party to the conversation on the behavior of the other party (the agent). Such effects have been predicted theoretically [15], and shown experimentally [16], but are rarely examined in real-life service interactions.

5. We offer a methodological contribution, of documenting the use of archives of data accrued on service platforms, and objective automated analyses of customer emotions and agent behavior, overcoming shortcomings of previous research, which relied extensively on self-report $[3,14]$.

\section{Framework and Hypotheses}

To introduce the theoretical idea that workload includes psychological features of a service conversation, we rely on available research in cognitive psychology and organizational behavior. Below, we first develop our hypotheses, and then describe the empirical study we conducted, which confirmed that the degree of cognitive and emotional load that customers create for employees influences employees' response time.

\subsection{Cognitive Load}

We derived our hypotheses regarding cognitive load from findings that people have a limited amount of what is called Working Memory [17], and are thus "bounded" in the amount of information they can process at any given time [18]. Service agents are also likely to need more time to comprehend a customer who presents more information.

Processing too much information also creates fatigue, hampering people's focus, and increasing the likelihood of errors [19]. The combination of limited working memory and fatigue created by processing a lot of information suggests that when customers present more information to a service agent they increase the cognitive load on the agent, and slow the agent down. We thus predict that cognitive load created by a customer increases the time it takes a service agent to respond to the customer:

Hypothesis 1 Cognitive load increases the response time of an agent to a customer;

Importantly, our prediction connects response timean aspect of employee behavior- to cognitive load-a feature of customer behavior, since it is a function of information customers bring into a conversation. Thus, this hypothesis relates the influence of one party of a conversation (a customer) on a second party to the same conversation (the service agent). Some experimental research documented such effects with regular dyads [20]. But to our knowledge the effects on actual real-life behavior of service agents, and in text based interactions, have not been shown.

\subsection{Emotional Load}

A second type of influence that we predict are of the emotions of a customer on the behavior of a service agent. Customers emotions can be positive, negative or neutral, but in any case can influence and provide additional information to service agents [21]. Emotional expressions in conversations provide useful information [22] ), but also require attention from agents, and trigger a need for Emotional Regulation [3] and Emotional Labor [23]. Processing customer emotional requires effort [24], requiring employees to recognize emotions that customers express and construe socially and organizationally appropriate responses [25]. Thus, customer emotion displays within a service conversation create a second type of load for service agents. We label this "Emotional Load", and we expect it to also increase the time it takes an employee to respond to a customer.

A competing analysis, however, could suggest that 
customer emotions "spice-up" a (service) job that is otherwise routine and repetitive. Customer service work can feel monotonous and dull, and customer emotions call-up different skills, such as emotional intelligence [26]. So customer emotions might add variety to an otherwise monotonous job [27], and [28] showed that task variety influences employee productivity. In this view, emotional aspects that a customer brings to a service conversation might motivate employees, and improve performance.

Alternately, certain types of customer emotional load might increase agent response time while other types reduce response time. This view would be consistent with documented nonlinear effects of stress [29] and operational system load [30]. Specifically, low and high values of emotional load can be expected to create higher agent response times than moderate emotional load. Agents are more likely to notice and be distracted by extreme emotion levels, while moderate levels can get lost for an agent who is immersed in work.

We therefore present two competing hypotheses regarding the effects of emotional load on agent response time:

Hypothesis 2a Emotional load increases the response time of a service agent to customers;

Hypothesis 2b There is a curvilinear relationship between emotional load and agent response time;

\section{Data Description and Definitions}

We utilize data provided by LivePerson Inc. (https://www.liveperson.com), a B-to-B organization that sells a platform for text-based service conversations. LivePerson servers mediate conversations between service-brand agents and customers, meaning that end-customers text-converse with service-agents; agents are employed by the service brand, and work through the LivePerson platform. Customers requesting a chatconversation are automatically transferred to available service agents, and wait if no agents are available. The service chat-conversation begins when an agent is assigned to a customer. A feature unique to chat service (unlike phone service) is that agents can simultaneously hold conversations with up to 3 customers. Service conversations comprise iterations of agent and customer messages, so an employee waiting for a specific customer to react can interact with other customers. A customer whose agent is busy with a different customer must wait, unaware of the reason for the delay.

We obtained data for a sample of 145,995 textservice conversations conducted between March 2016 and October 2017, of customers and service agents of a large western transportation company. The data includes employee lines, customer lines and system lines (i.e., lines generated automatically, that do not reflect any human behavior, and therefore removed from the current analysis). From here on we use the terms "chat" and "conversation" interchangeably, referring to full conversations between agents and customers, and the terms "line" and "message" interchangeably, referring to text presented together at a particular time in a conversation. Conversations thus comprise a sequence of messages from either a customer or an agent. Conversations lasted an average of 11.57 minutes $(S D=9.10)$, and had an average number of $5.20(S D=4.04)$ customer lines and $5.19(S D=4.22)$ employee lines.

A conversation is identified by customer ID, employee ID, and date. A line in the data represents a single message in a specific conversation. All lines include a time-stamp, a notation of who wrote the line (customer, agent, or system), number of words in the conversation. Customer lines also include a score of the emotion in the customer text (see below). The nature of these service conversations is highly sensitive, and includes things like credit card numbers and private addresses. We therefore could not get access to the full text of the conversations.

\subsection{Independent Variables}

We computed scores of two types of psychological load on service agents. Both scores are at the message level (i.e., for each message of a focal customer).

Cognitive load is scored by the number of words a customer wrote in a message. The total number of customer words in a conversation defines the cognitive load a conversation creates for an employee.

Emotional load is scored for each line in a conversation using the sentiment analysis described in [31]. In theory line scores can range from -7 to +7 , but effectively $(99 \%)$ scores are between -2 and +2 . Scores of all lines in a conversation are aggregated to designate the emotion load of the conversation. This means a conversation can have an emotion score of zero (0) if it has identical amounts of positive and negative emotions; this occurred in less than $5 \%$ of all the conversations, and the pattern of results with a sample that excluded these conversations is identical.

More details on the emotion coding are available in [31], which also reports validation (Precision and Recall) results, and initial insights provided by this tool with a different set of data. Specifically [31] report a clear relationship between the emotion pattern in a conversation and subsequent customer satisfaction.

For some analyses we also compute a score of cog- 
nitive load and emotional load of intervals (a sub-set of messages) within a conversation (see below). In these aggregations a section can potentially have an emotion score of zero (0) if it has identical amounts of positive and negative emotions. Here as well, this occurred in a negligible subset of conversations, and comparing results of our analyses with and without intervals that had an emotion score of zero revealed a similar pattern of results.

\subsection{Control Variables}

The data were hashed to ensure anonymity, and we could not contact or obtain demographics of customers or employees, or obtain the raw text of conversations. As noted, customer service conversations include highly confidential information that is impossible to mask, and can hamper customer anonymity even after masking attempts [32].

We added control variables that might be considered alternative predictors, or influence effects of psychological load on employee response time. Variables include employee ID (to account for individual differences), day of the week (to account for weekday and weekend effects), time of day (to account for morning, afternoon and evening effects), and nature of conversation (sales or service). Additional controls include mean customer response time, mean number of employee words, number of parallel conversations, and extent to which employee is active in these conversations (see Table 1).

Our analyses account for system load by including the number of customers waiting in the queue and the number of employees active in the system. The analyses also account for the complexity of customer requests by including the duration (length in seconds) of the total conversation, assuming that more complex requests take longer. Descriptive statistics are presented in Table 2. Descriptives of three nominal variables (day, time, and request) are not included in the table, and are as follows: $71 \%$, of conversations were during Weekdays, (29\% during Weekend); $28 \%$ of conversations were in the morning, $25 \%$ around noon, $47 \%$ in the evening; and $46 \%$ were sales while $54 \%$ were support conversations.

\subsection{Dependent Variable}

Agent response time is operationally defined as the mean response time of an agent to a focal customer over all messages in a conversation. This variable includes the time it takes an employee to read, process, and respond to all a focal customer's messages (defined as agent service time), and time in which an agent interacts with other customers, which we call "employee other time" (see Tables 1 and 2). For robustness, we

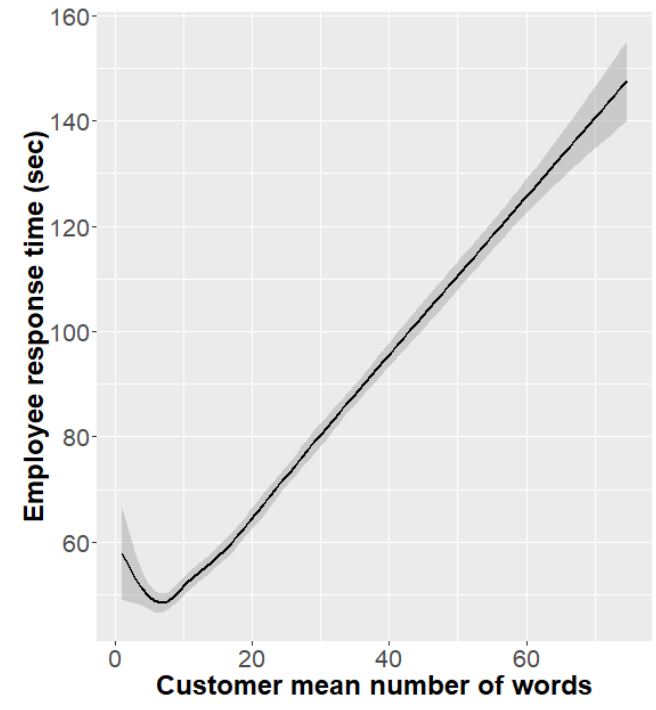

Figure 1. Employee response time as a function of cognitive load (number of customer words) normalized by duration of a conversation. Gray area around the curves is the $95 \%$ confidence interval.

also tested our hypotheses regarding employee response time after subtracting employee other time from agent response time, and the results were similar. For brevity we report here only the results regarding complete response time.

\section{Results}

Figure 1 plots the relationship between cognitive load and agent response time, and Figure 2 between emotional load and agent response time. Figures 1 and 2 suggest a relationship of cognitive load and emotional load to employee response time, offering initial support of our hypotheses. We first tested all hypotheses on full conversations, using the R ([33]) lme4 [34] and lmerTest [35] packages for Hierarchical Linear Modeling (HLM). Then, to support our causal predictions we conducted a causal analysis within conversations. Our analyses first confirm the correlative effects (Section 4.1, and then the causal (predictive) effects of emotional and cognitive load on agent response time (Section 4.2).

\subsection{Psychological Load and Agent Response Time: Conversation Level Analyses}

All continuous variables in this analysis are aggregated to the full conversation; independent and control variables are scaled, so HLM provided a test of the relationship between load variables within a conversation and agent response time within the same conversation. This analysis confirmed a positive relationship between 
Table 1. Labels and coding of control variables

\begin{tabular}{l|l}
\hline Measure & Description and coding \\
\hline ID & Identification number for each of the 53 service agents \\
Is_weekend & Weekdays/Weekends: Mon-Fri =0, Sat-Sun = 1 \\
Hour of day & Morning 8:00-11:59AM, Noon 12:00-5:59PM, or Evening 6:00-11:00PM \\
Nature of conversation & Type of service - whether conversation was customer support (0) or sales (1) \\
Customer response time & Mean customer response time in an interval/total conversation (in seconds) \\
Number of agent words & Mean number of agent words in an interval/total conversation \\
Number of agent parallel conversations & Weighted average of number of parallel chats during an interval/total conversation \\
Number of words agent wrote to others & Mean number of words an agent wrote to other customers during a chat/interval \\
Number of words agent received from others & Mean number of words an agent received from other customers during an interval/total conversation \\
Agent other time (in seconds) & Time that agents spend serving other customers, creating a wait for focal customer \\
Duration of conversation (in seconds) & Customer length of stay in a focal conversation \\
Number of active agents & Number of agents currently working in the system \\
\hline
\end{tabular}

Table 2. Means, standard deviations, and inter-correlations of study variables

\begin{tabular}{|c|c|c|c|c|c|c|c|c|c|c|c|c|c|}
\hline Variable & $M$ & $S D$ & 1 & 2 & 3 & 4 & 5 & 6 & 7 & 8 & 9 & 10 & 11 \\
\hline 1 Number of people in queue & 3.31 & 4.18 & & & & & & & & & & & \\
\hline 2 Agent response time (in seconds) & 75.38 & 79.5 & $.01 * *$ & & & & & & & & & & \\
\hline 3 Agent service time (in seconds) & 40.30 & 31.8 & $.02 * *$ & $.44 * *$ & & & & & & & & & \\
\hline 4 Agent other time (in seconds) & 35.08 & 71.43 & $.01^{* *}$ & $.92^{* *}$ & $.05^{* *}$ & & & & & & & & \\
\hline 5 Number of agent parallel conversations & 2.28 & 0.72 & $.02 * *$ & $.07 * *$ & $-.17 * *$ & $.15^{* *}$ & & & & & & & \\
\hline 6 Number of agent words & 36.22 & 16.37 & $.03 * *$ & $.40^{* *}$ & $.29 * *$ & $.32 * *$ & $-.02 * *$ & & & & & & \\
\hline 7 Number of words agent wrote to others & 28.36 & 76.41 & 0 & $.33^{* *}$ & $-.02 * *$ & $.38^{* *}$ & $.12 * *$ & $.12 * *$ & & & & & \\
\hline 8 Number of words agent received from others & 12.24 & 33.46 & 0 & $.34 * *$ & $.02 * *$ & $.37 * *$ & $.12 * *$ & $.11^{* *}$ & $.92 * *$ & & & & \\
\hline 9 Duration of conversation (in seconds) & 694.34 & 546.05 & .0 & $.25^{* *}$ & $.16^{* *}$ & $.20 * *$ & $.13^{* *}$ & $.02 * *$ & $.09 * *$ & $.09 * *$ & & & \\
\hline 10 Number of words customer wrote & 15.81 & 9.19 & $.03^{* *}$ & $.18^{* *}$ & $.18^{* *}$ & $.13^{* *}$ & $.02 * *$ & $.22 * *$ & $.05^{* *}$ & $.06^{* *}$ & $.03 * *$ & & \\
\hline 11 Customer response time (in seconds) & 55.28 & 35.53 & .0 & $.17^{* *}$ & $.15^{* *}$ & $.12^{* *}$ & $.07 * *$ & $.18^{* *}$ & $.04 * *$ & $.04 * *$ & $.23 * *$ & $.38 * *$ & \\
\hline 12 Customer emotion & 0.06 & 0.33 & $.01^{*}$ & $-.08 * *$ & $-.04 * *$ & $-.07 * *$ & $-.02 * *$ & $.02 * *$ & $-.03 * *$ & $-.03 * *$ & $-.05 * *$ & $-.03 * *$ & $-.06 * *$ \\
\hline
\end{tabular}

Notes: * indicates $p<.05$; ** indicates $p<.01$.

$M$ and $S D$ represent mean and standard deviation, respectively.

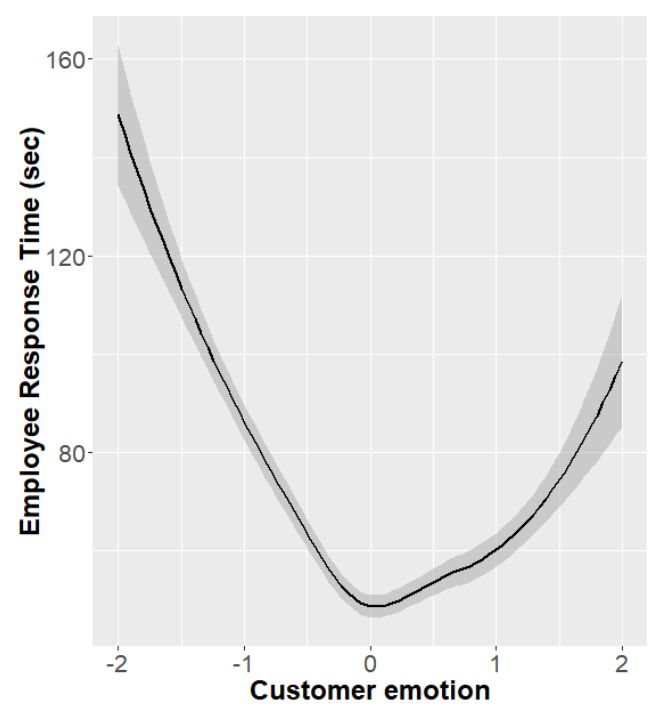

Figure 2. Employee response time as a function of customer emotion normalized by duration of a conversation.. The gray area around the curve represents $95 \%$ confidence interval. cognitive load and response time: an increase of one $S D$ in cognitive load is related to an increase in 5.63 seconds in agent response time $(\gamma=5.63, p<0.001$; see Table 3), supporting Hypothesis 1 . This means that for an average conversation, in which employees send 5.19 messages, the increase in agent response time sums to a total of 29.22 seconds.

The findings show a significant effect of customeremotion $(\gamma=-4.64, p<0.001)$ and squaredcustomer-emotion ( $\gamma=0.27, p<0.001 ;$ ), indicating a curvilinear relationship between emotional load and agent response time (see Table 3). Lowest and highest values of customer emotion are related to higher agent response time, supporting Hypothesis $2 \mathrm{~b}$ over Hypothesis $2 \mathrm{a}$.

These results confirm relationships between psychological load and agent response time. Our hypotheses, however, predicted causal effects of load on agent response time, and a relationship may reflect effects in the opposite direction than we predicted. In addition, these results regard a single emotion variable, that varies from very negative to very positive. Psychology, however, supports positive and negative emotion as independent factors [37, 38]. In a second analysis, we therefore separate between the effects of positive and negative emotions, and test causal effects on agent response time at $T_{2}$, of prior cognitive and emotional loads on an agent (i.e., at $T_{1}$ ). 
Table 3. HLM regression predicting agent response time

\begin{tabular}{|c|c|c|c|c|c|}
\hline & \multirow[b]{2}{*}{ Variable } & \multicolumn{2}{|c|}{ Model 1} & \multicolumn{2}{|c|}{ Model 2} \\
\hline & & $\gamma$ & $S E$ & $\gamma$ & $S E$ \\
\hline \multicolumn{6}{|c|}{ Variance Components } \\
\hline & Within-group variance (Level 1) & 6,705 & & & \\
\hline & Between-group variance (Level 2) & 328 & & & \\
\hline \multicolumn{6}{|l|}{ Fixed Effects } \\
\hline & (Intercept) & $79.29 * * *$ & 2.69 & $64.55^{* * *}$ & 3.04 \\
\hline & Number of words customer wrote & & & $5.63 * * *$ & .19 \\
\hline & Customer emotion & & & $-4.64 * * *$ & .17 \\
\hline & Customer-emotion-squared & & & $.27 * * *$ & .04 \\
\hline & Customer response time & & & -.15 & .19 \\
\hline & Duration of conversation & & & $.03 * * *$ & .0003 \\
\hline & Number of agent parallel conversations & & & $3.14 * * *$ & .2 \\
\hline & Number of agent words & & & $27.94 * * *$ & .19 \\
\hline & Number of words agent wrote to others & & & $9.93^{* * *} *$ & .45 \\
\hline & Number of words agent received from others & & & $12.10^{* * *}$ & .45 \\
\hline & Skill: Sales & & & $-10.72 *$ & 4.34 \\
\hline & Hour of Day & \multirow{2}{*}{\multicolumn{2}{|c|}{ Not included }} & \multicolumn{2}{|c|}{ Included } \\
\hline & Is_weekend & & & \multicolumn{2}{|c|}{ Included } \\
\hline & Number of people in queue & & & $-.88^{* * *} *$ & .18 \\
\hline \multicolumn{2}{|l|}{ AIC } & \multicolumn{2}{|c|}{1687590.2} & \multicolumn{2}{|c|}{1634596.1} \\
\hline \multicolumn{2}{|l|}{ Log Likelihood } & \multicolumn{2}{|c|}{-843792.1} & \multicolumn{2}{|c|}{-817281.1} \\
\hline \multicolumn{2}{|l|}{ Pseudo $-R^{2}$} & & & \multicolumn{2}{|c|}{$29.6 \%$} \\
\hline
\end{tabular}

\subsection{Psychological Load as a Cause of Agent Response Time: Causal Effects Within Conversations}

To test the causal effect of psychological load on agent response time, we moved from analyses of complete conversations to testing effects within conversations.

In this analysis we also explore effects of positive vs. negative emotions, by further dividing emotion load into two types: Positive Customer Emotion Load (e.g., happiness, pleasantness; customer emotion values $>0$ ), and Negative Customer Emotion Load (e.g., anger, frustration; customer emotion values $<0$ ).

We defined a segment of a conversation as $T_{1}$, and a subsequent segment as $T_{2}$. We used segments of 4 customer lines as the predictor $\left(T_{1}\right)$, building on [39] who showed that analyses of service agents' written communication is optimal with four lines. The dependent variable in this analysis is the average response time of an agent in two (2) messages, that define $T_{2}$ of the analysis. We use two (2) messages because a measure based on only one (1) message is less reliable, and susceptible to random variations [40], while a measure with too many agent messages is also inappropriate for this analysis, because the IV (customer emotion load) creates short term effects, that can diffuse quickly, and especially when an agent is working under time pressure, which is the case with service agents. Hence, $T_{2}$ is the mean response time of 2 agent messages that follow four (4) customer messages in $T_{1}$, which created the load predicted to influence the agent behavior.

The definitions of the size of the sections of conversations for this (causal) analysis reduced the sample of data we could analyze, because the excluded some conversations: Some conversations did not meet have a section of at least four customer messages $\left(T_{1}\right)$ followed by at least two subsequent agent messages (in $T_{2}$ )), and these were excluded from the analysis. The effective sample for this analysis was therefore 48,837 conversations; the average duration of these conversations is 17 minutes and 28 seconds $(S D=11$ minutes and 30 seconds). Within each conversation in this sample we randomly selected a time point, computed the emotional load (mean emotion scores of the four customer lines prior to this point), and the the response time of the two agent (mean of two messages following this point).

As a robustness check, we also used a different measure of agent activity in parallel conversations in this analysis. In the previous analyses we used the number of words the agent wrote and received from other (parallel) customers. In the current analyses we used the time the agents spent serving other customers within the selected time interval. We also added to this analysis a control variable, the number of active agents in the system, to control for social facilitation or social loafing effects on performance [41]. Removing these control variables did not change our core findings, while adding them added power to our significant findings. Finally, we also tested for effects in the opposite direction from our analyses (i.e., tested for agent response time influencing customer emotions). This yielded insignificant results, ruling this out as an alternative explanation.

The results of our analyses confirm an influence of cognitive load at $T_{1}$ on agent response time at $T_{2}$ $(\gamma=0.91, p<0.001$; see Table 4$)$, fully supporting Hypothesis 1. The results also support the pre- 
dicted effects of emotional load on agent response time with Positive Emotional Load: Customer positive emotion at $T_{1}$ had a U-shaped effect on agent response time at $T_{2}\left(\gamma_{\text {positive_emotion }}=-2.85, p<0.001\right.$; $\gamma_{\text {positive_emotion }}{ }^{2}=1.36, p<0.001$; see Table 4). This means that a moderate amount of customer positive emotion reduced agent response time, while high and low levels of positive emotion increased agent response time, which supports our Hypothesis $2 b$.

However, emotional load created by customer negative emotion shows a linear (rather than curvilinear) effect on agent response time. ${ }^{1}$. An increase in negative emotion at $T_{1}$ consistently increases agent response time at $T_{2}\left(\gamma_{\text {negative_emotion }}=0.49, p<0.05\right.$; see Table 4$)$, with no curvilinear effect of negative emotional load $\left(\gamma_{\text {negative_emotion }}{ }^{2}=-0.21, p>0.05\right)$.

As a final leg, we tested a potentially competing prediction (and a popular assumption), that agent response time influences (rather than is influenced by) customer emotion, since customers are presumed to be upset when an agent takes a long time to respond. However, our analyses refute this direction of causality, showing no significant effect of agent response time on customer negative emotion (detailed results are available from the authors).

\section{Discussion and Future Work}

Our study provides a new perspective for understanding service systems and for integrating automated sentiment analyses and operational measures into tests of hypotheses that are based on research in psychology. Specifically, we test and show effects of customers on the behavior of service agents, and follow the logic of [6], to show that system level studies of service overlook important dynamics that occur within individual service conversations. Our analyses also highlight great opportunities afforded by data that is increasingly available in service organizations on the content and behaviors of agents and customers in service conversations. Timestamps and other documentation of agent and customer behavior are automatically documented by service systems, and provide excellent data for research on service dynamics [42].

Our theoretical contribution is that workload comprises Psychological Load (in addition to system load, which is the number of people served). Psychological load includes cognitive and emotional aspects, and means that planning and managing service systems requires a look beyond the count of number of customers. The cognitive and emotional states created by a cus-

\footnotetext{
${ }^{1}$ Note that in this analysis we use absolute values of negative customer emotion, hence values are $>0$.
}

tomer in a service conversation add factors with which employees must cope, and determine how quickly an agent responds. That customers who write more and express high emotions gets lost when load is defined based only on counts of the number of people or tasks that service comprises. The idea of "micro-level influences" in service systems, influences that occur at the level of a conversation between a specific employee and a specific customer, can and should be extended to other types of service and other types of influence. We use the number of words a customer uses as a proxy for cognitive load, and the novelty, complexity or repetitiveness of the words, might compound the cognitive load. Future research might attempt to focus more on such nuances of information a customer conveys, since it can further promote understanding of service conversations.

Emotional load, in turn, is shown to have a U-shaped relationship with employee response time; but a causal( time-based) analysis shows that customer expression of negative emotion hampers employee efficiency at any level, with increasing damage to agent response time with more intense negative customer emotion. This is an important validation of research in psychology that used traditional psychological research methods (e.g., experimental manipulations with small samples and self-report measures, cf. [43, 44]), with "the real world" "Big Data." The finding that customer happiness or unhappiness is a factor that influences behaviors of service agents is also an important statement that challenges the tendency to treat customer emotion as an outcome, or a result of the behavior of service agents. Our analyses support the ideas presented by [24], of emotions bringing additional tasks into any work situation. However additional research is needed to examine the emotional dynamics of agents, which our methods did not allow. Fore example, the question of whether emotional labor mediates the effects we show is left for future research, and requires tools for assessing emotions of service agents, something that the tool developed by[31] does not allow.

Our theoretical analyses suggested alternative ways in which customer emotion may influence employees. Theoretically, expressed emotions may require additional effort from employees, because they require processing. Alternately, customer emotions can provide variety and feedback in an otherwise monotonous job, which can create motivation for service agents [27, 45]. Our findings cannot discern between these two dynamics, so additional research must untangle these possibilities. Alternately, perhaps instead of a our focus on emotion valance (i.e., positive and negative), future research an consider effects of discrete emotions (i.e., anger, frustration, delight) as some researchers advocate [46]. Cus- 
Table 4. HLM regression predicting agent response time at $T_{2}$

\begin{tabular}{|c|c|c|c|c|c|}
\hline \multirow{2}{*}{\multicolumn{2}{|c|}{ Variable }} & \multicolumn{2}{|c|}{ Model 1} & \multicolumn{2}{|c|}{ Model 2} \\
\hline & & $\gamma$ & $S E$ & $\gamma$ & $S E$ \\
\hline \multicolumn{6}{|c|}{ Variance Components } \\
\hline & Within-group variance (Level 1) & 2,680 & & & \\
\hline & Between-group variance (Level 2) & 298 & & & \\
\hline \multicolumn{6}{|l|}{ Fixed Effects } \\
\hline & (Intercept) & $67.27 * * *$ & 2.61 & $72.18 * * *$ & 2.82 \\
\hline \multicolumn{6}{|c|}{ Independent variables $\left(T_{1}\right)$} \\
\hline & Number of words customer wrote $T_{1}$ & & & $0.91 * * *$ & 0.14 \\
\hline & Customer positive emotion $T_{1}$ & & & $-2.85 * * *$ & 0.24 \\
\hline & Customer positive emotion ${ }^{2} T_{1}$ & & & $1.36^{* * *}$ & 0.23 \\
\hline & Customer negative emotion $T_{1}$ & & & $0.49 *$ & 0.23 \\
\hline & Customer negative emotion ${ }^{2} T_{1}$ & & & -0.21 & 0.23 \\
\hline \multicolumn{6}{|c|}{ Control variables $\left(T_{1}\right)$} \\
\hline & Number of agent parallel conversations $T_{1}$ & & & $-2.51 * * *$ & 0.15 \\
\hline & Number of active agents & & & 0.18 & 0.14 \\
\hline & Number of agent words $T_{1}$ & & & $-0.88 * * *$ & 0.14 \\
\hline & Agent other time $T_{1}$ & & & $0.94 * * *$ & 0.14 \\
\hline & Customer response time $T_{1}$ & & & $1.66^{* * *}$ & 0.15 \\
\hline \multicolumn{6}{|c|}{ Control variables $\left(T_{2}\right)$} \\
\hline & Agent other time $T_{2}$ & & & $41.36 * * *$ & 0.13 \\
\hline & Number of agent words $T_{2}$ & & & $7.24 * * *$ & 0.13 \\
\hline & Number of words customer wrote $T_{2}$ & & & $4.11 * * *$ & 0.13 \\
\hline & Customer positive emotion $T_{2}$ & & & $-0.63 * * *$ & 0.13 \\
\hline & Customer negative emotion $T_{2}$ & & & $0.57 * * *$ & 0.13 \\
\hline \multicolumn{6}{|c|}{ Control variables } \\
\hline & Number of people in queue & & & -0.21 & 0.13 \\
\hline & Duration of conversation & \multirow{4}{*}{\multicolumn{2}{|c|}{$\begin{array}{l}\text { Not included } \\
\text { Not included }\end{array}$}} & $3.62 * * *$ & 0.14 \\
\hline & Is_weekend & & & \multicolumn{2}{|c|}{ Included } \\
\hline & Hour of Day & & & \multicolumn{2}{|c|}{ Included } \\
\hline & Skill: Sales & & & -6.14 & 3.8 \\
\hline AIC & & 524,28 & & 456,4 & \\
\hline Log Likelihood & & $-262,1$ & & -228 & \\
\hline Pseudo - $R^{2}$ & & & & 66.3 & \\
\hline
\end{tabular}

tomer anger, for instance, is likely have a different influence than customer guilt, since anger is a motivating emotion that puts the blame on the target (in this case the agent or the organization) [47] while guilt suggests the customer retains the responsibility for whatever is the issue.

The emotional load effects we found are constrained by the accuracy of available tools, including the tool that we used. Accurate detection of emotion in written conversations is in itself a new venture, that requires additional research. Research attention invested in detecting emotion in Twitter conversations (c.f., [48]), might be expanded to other forms of written communication (chat, SMS, email). This means, however, that our analyses and results are a conservative test of the effects of psychological load. Our detection of emotional load effectively recalls only some of the emotions that customers actually present ( $24 \%$ of cases of negative customer emotion and $77 \%$ of cases of positive customer emotion). Our detection of cognitive load looked, as noted above, only at number of words. The emotional and cognitive influences that our analyses could not identify are a part of the statistical "noise" in our analyses and results. Improving available tools for studying psychological load is something that big-data research of service delivery must embark upon. The bottom line of our research is that service operations and service researchers must acknowledge dynamics that customers bring to the system, which can slow down employees' work and the efficiency of service systems. Failing to recognize customer induced states will lead to continued oversight and poor service management.

\section{References}

[1] D. S. Kc and C. Terwiesch, "Impact of Workload on Service Time and Patient Safety: An Econometric Analysis of Hospital Operations," Management Science, vol. 55, pp. 1486-1498, 2009.

[2] L. A. Witt, M. C. Andrews, and D. S. Carlson, "When conscientiousness isnt enough: Emotional exhaustion and performance among call center customer service representatives," Journal of Management, vol. 30, no. 1, pp. 149-160, 2004.

[3] A. A. Grandey, D. N. Dickter, and H.-P. Sin, "The customer is not always right: Customer aggression and emotion regulation of service employees," Journal of Organizational Behavior, vol. 25, no. 3, pp. 397-418, 2004.

[4] A. Rafaeli and R. I. Sutton, "Busy stores and demanding customers: How do they affect the display of positive emotion?," Academy of Management Journal, vol. 33, no. 3, pp. 623-637, 1990.

[5] D. D. Walker, D. D. van Jaarsveld, and D. P. Skarlicki, "Sticks and stones can break my bones but words can also hurt me: The relationship between customer verbal 
aggression and employee incivility," Journal of Applied Psychology, vol. 102, no. 2, pp. 163-179, 2017.

[6] R. J. Batt and C. Terwiesch, "Doctors Under Load : An Empirical Study of State-Dependent Service Times in Emergency Care," Working Paper, pp. 1-32, 2012.

[7] C. Dormann, S. Brod, and S. Engler, "Demographic change and job satisfaction in service industries-the role of age and gender on the effects of customer-related social stressors on affective well-being," SMR-Journal of Service Management Research, vol. 1, no. 1, pp. 57-70, 2017.

[8] S. D. Pugh, "Service with a smile: Emotional contagion in the service encounter," Academy of Management Journal, vol. 44, no. 5, pp. 1018-1027, 2001.

[9] S. Fernie and D. Metcalf, (Not) hanging on the telephone: payment systems in the new sweatshops. Centre for Economic Performance, London School of Economics and Political Science, 1998.

[10] C. Jasmand, V. Blazevic, and K. De Ruyter, "Generating sales while providing service: A study of customer service representatives' ambidextrous behavior," Journal of Marketing, vol. 76, no. 1, pp. 20-37, 2012.

[11] A. B. Bakker and E. Demerouti, "The job demandsresources model: State of the art," Journal of managerial psychology, vol. 22, no. 3, pp. 309-328, 2007.

[12] R. Batt, D. Holman, and U. Holtgrewe, "The globalization of service work: Comparative institutional perspectives on call centers: Introduction to a special issue of the industrial \& labor relations review," ILR Review, vol. 62, no. 4, pp. 453-488, 2009.

[13] D. Holman, R. Batt, and U. Holtgrewe, "The global call center report: International perspectives on management and employment," 2007.

[14] S. I. Donaldson and E. J. Grant-Vallone, "Understanding self-report bias in organizational behavior research," Journal of Business and Psychology, vol. 17, no. 2, pp. 245-260, 2002.

[15] S. Hareli and A. Rafaeli, "Emotion cycles: On the social influence of emotion in organizations," Research in organizational behavior, vol. 28, pp. 35-59, 2008.

[16] R. B. Cialdini, Influence: Science and practice. Boston: Allyn and Bacon, 2000.

[17] A. Baddeley, "Working memory (Oxford Psychology Series No. 11)," 1986.

[18] H. A. Simon, "Theories of bounded rationality," Decision and organization, vol. 1, no. 1, pp. 161-176, 1972.

[19] S. E. Hobfoll, "Conservation of resources: A new attempt at conceptualizing stress," The American Psychologist, vol. 44, pp. 513-524, 1989.

[20] G. A. Van Kleef, A. C. Homan, and A. Cheshin, "Emotional influence at work: Take it EASI," Organizational Psychology Review, vol. 2, no. 4, pp. 311-339, 2012.

[21] G. A. Van Kleef, "How emotions regulate social life: the emotions as social information (EASI) model," Current Directions in Psychological Science, vol. 18, no. 3, pp. 184-188, 2009.

[22] G. A. Van Kleef, C. K. W. De Dreu, and A. S. R. Manstead, "The interpersonal effects of anger and happiness in negotiations," Journal of Personality and Social Psychology, vol. 86, no. 1, p. 57, 2004.
[23] A. Rafaeli and R. I. Sutton, "Expression of emotion as part of the work role," Academy of Management Review, vol. 12, no. 1, pp. 23-37, 1987.

[24] H. M. Weiss and R. Cropanzano, "Affective Events Theory: A theoretical discussion of the structure, causes and consequences of affective experiences at work," $R e$ search in Organizational Behavior, vol. 18, no. 1, pp. 174, 1996.

[25] D. Geddes and R. R. Callister, "Crossing the line (s): A dual threshold model of anger in organizations," Academy of Management Review, vol. 32, no. 3, pp. 721746, 2007.

[26] J. D. Mayer and G. Geher, "Emotional intelligence and the identification of emotion," Intelligence, vol. 22, no. 2, p. 89, 1996.

[27] J. Hackman and G. Oldham, "Motivation through the design of work: Test of a theory," Organizational Behavior and Human Performance, vol. 16, no. 2, pp. 250-279, 1976.

[28] B. R. Staats and F. Gino, "Specialization and Variety in Repetitive Tasks: Evidence from a Japanese Bank," Management Science, vol. 58, pp. 1141-1159, jun 2012.

[29] R. M. Yerkes and J. D. Dodson, "The relation of strength of stimulus to rapidity of habitformation," Journal of Comparative Neurology, vol. 18, no. 5, pp. 459-482, 1908.

[30] J. A. Berry Jaeker and A. L. Tucker, "Past the point of speeding up: The negative effects of workload saturation on efficiency and patient severity," Management Science, vol. 63, no. 4, pp. 1042-1062, 2017.

[31] G. B. Yom-Tov, S. Ashtar, D. Altman, M. Natapov, N. Barkay, M. Westphal, and A. Rafaeli, "Customer sentiment in web-based service interactions: automated analyses and new insights," in $W W W$ ' 18 Companion: The 2018 Web Conference Companion, (Lyon, France), 2018.

[32] M. Barbaro, T. Zeller, and S. Hansell, "A face is exposed for aol searcher no. 4417749," New York Times, vol. 9, no. 2008, p. 8, 2006.

[33] R. C. Team, "R: A Language and Environment for Statistical Computing," 2014.

[34] D. Bates, M. Mächler, B. Bolker, and S. Walker, "Fitting Linear Mixed-Effects Models Using \{lme4\}," Journal of Statistical Software, vol. 67, no. 1, pp. 1-48, 2015.

[35] A. Kuznetsova, P. Bruun Brockhoff, and R. Haubo Bojesen Christensen, "lmerTest: Tests in Linear Mixed Effects Models," 2016.

[36] T. Snijders and R. Bosker, Multilevel modeling: An introduction to basic and advanced multilevel modeling. Sage, 2012.

[37] D. Watson and A. Tellegen, "Toward a consensual structure of mood.," Psychological bulletin, vol. 98, no. 2, p. 219, 1985.

[38] J. T. Larsen and A. P. McGraw, "Further evidence for mixed emotions," Journal of Personality and Social Psychology, 2011.

[39] J. Herzig, G. Feigenblat, M. Shmueli-Scheuer, D. Konopnicki, A. Rafaeli, D. Altman, and D. Spivak, "Classifying Emotions in Customer Support Dialogues in Social Media," in 17th Annual Meeting of SIGDIAL, p. 64, 2016. 
[40] R. Rosenthal and R. Rosnow, Essentials of behavioral research: Methods and data analysis. McGraw-Hill Humanities Social, 1991.

[41] B. Latané, K. Williams, and S. Harkins, "Many hands make light the work: The causes and consequences of social loafing.," Journal of Personality and Social Psychology, 1979.

[42] A. Rafaeli, D. Altman, D. D. Gremler, M.-H. Huang, D. Grewal, B. Iyer, A. Parasuraman, and K. de Ruyter, "The future of frontline research: Invited commentaries," Journal of Service Research, vol. 20, no. 1, pp. 91-99, 2017.

[43] A. Rafaeli, A. Erez, S. Ravid, R. Derfler-Rozin, D. EfratTreister, and R. Scheyer, "When customers exhibit verbal aggression, employees pay cognitive costs," Journal of Applied Psychology, vol. 97, no. 5, p. 931, 2012.

[44] A. A. Grandey, G. M. Fisk, A. S. Mattila, K. J. Jansen, and L. A. Sideman, "Is ?service with a smile? enough? Authenticity of positive displays during service encounters," Organizational Behavior and Human Decision Processes, vol. 96, no. 1, pp. 38-55, 2005.

[45] B. Gutek, A. Bhappu, and M. Liao-Troth, "Distinguishing between service relationships and encounters.,"Journal of Applied Psychology, vol. 84, no. 2, p. 218, 1999.

[46] R. S. Lazarus and Y. Cohen-Charash, Discrete emotions in organizational life. 2001.

[47] C. S. Carver and E. Harmon-Jones, "Anger is an approach-related affect: evidence and implications.," Psychological Bulletin, vol. 135, no. 2, p. 183, 2009.

[48] A. Sarlan, C. Nadam, and S. Basri, "Twitter sentiment analysis," in Information Technology and Multimedia (ICIMU), pp. 212-216, IEEE, 2014. 